\title{
LncRNA GASL1 is downregulated in chronic heart failure and regulates cardiomyocyte apoptosis
}

Haihong Deng ${ }^{1}$, Wenbo Ouyang ${ }^{1}$, Li Zhang ${ }^{3}$, Xiaoshan Xiao ${ }^{4}$, Zhiyong Huang ${ }^{3^{*}}$ and Wendian Zhu ${ }^{2^{*}}$

\author{
* Correspondence: huzhgy@gmail. \\ com; j159911@163.com \\ ${ }^{3}$ Department of Anesthesiology, \\ Fuwai Hospital Chinese Academy of \\ Medical Sciences, No. 12 Langshan \\ Road, Shenzhen City 518057, \\ People's Republic of China \\ ${ }^{2}$ Department of General Surgery, \\ The First People's Hospital of \\ Zhaoqing, No. 9 Donggang East \\ Road, Duanzhou District, Zhaoging \\ City, Guangdong Province 526000, \\ People's Republic of China \\ Full list of author information is \\ available at the end of the article
}

\begin{abstract}
Background: TGF- $\beta 1$ contributes to chronic heart failure. It is known that IncRNA GASL1 can inactivate TGF- $\beta 1$ in cancer biology.

Methods: All the participants were enrolled in the First People's Hospital of Zhaoqing during the period June 2012 to June 2013. ELISA, RT-qPCR, vectors, transient transfections and western blot were carried out during the research.

Results: We found that plasma levels of TGF- $\beta 1$ were significantly higher, while levels of GASL1 in plasma were significantly lower in chronic heart failure (CHF) patients compared to the control group. TGF- $\beta 1$ and GASL1 were inversely correlated in CHF patients. Low pretreatment plasma levels of GASL1 were closely associated with poor survival of CHF patients. GASL1 expression was not significantly affected by TGF- $\beta 1$ overexpression in cardiomyocytes, while cardiomyocytes with GASL1 overexpression showed downregulated TGF- $\beta 1$. Overexpression of GASL1 led to a decreased, while TGF- $\beta 1$ overexpression led to an increased apoptotic rate of cardiomyocytes under $\mathrm{H}_{2} \mathrm{O}_{2}$ treatment. In addition, TGF- $\beta 1$ overexpression attenuated the effect of GASL1 overexpression.
\end{abstract}

Conclusion: In conclusion, GASL1 was downregulated in CHF. GASL1 overexpression may improve CHF by inhibiting cardiomyocyte apoptosis through the inactivation of TGF- $\beta 1$.

Keywords: Chronic heart failure, IncRNA GASL1, TGF- $\beta 1$, Apoptosis

\section{Background}

Heart diseases cause more deaths than the sum of all types of cancer [1]. In effect, heart diseases, such as chronic heart failure (CHF), are the leading cause of hospital admission in many regions of the world [2]. In the United States, CHF is responsible for 1 out of 9 deaths [3], and 35 billion US dollars are spent on its prevention and treatment [4]. Occurrence of CHF is closely correlated with many other clinical disorders, such as hypercholesterolemia, hypertension, and diabetes mellitus [5]. With the growth of aging population, the incidence rate of CHF is predicted to further increase all over the world [5]. Therefore, development of novel therapeutic targets is urgently needed to improve the survival of CHF patients.

Studies on heart failures have revealed that many factors are related to the disease development, while genetic factors play central roles in this process [6, 7]. Long noncoding RNAs (lncRNAs, > $200 \mathrm{nt}$ ) have critical roles in heart failure by regulating

(c) The Author(s). 2019 Open Access This article is distributed under the terms of the Creative Commons Attribution 4.0 International License (http://creativecommons.org/licenses/by/4.0/), which permits unrestricted use, distribution, and reproduction in any medium, provided you give appropriate credit to the original author(s) and the source, provide a link to the Creative Commons license, and indicate if changes were made. The Creative Commons Public Domain Dedication waiver (http://creativecommons.org/ publicdomain/zero/1.0/) applies to the data made available in this article, unless otherwise stated. 
expression of related genes [8]. GASL1 is a recently characterized tumor suppressive lncRNA in cancer biology $[9,10]$. A recent study reported that GASL1 regulated lung cancer cell growth by inactivating TGF- $\beta 1$ [10], which contributes to the development of heart failure [11]. We therefore investigated the roles of GASL1 in CHF.

\section{Materials and methods}

\section{Patients}

The patient group in this study included 72 CHF patients (40 males and 32 females, 44 to 74 years, $56.6 \pm 6.3$ years). The control group included 66 healthy volunteers (40 males and 32 females, 44 to 74 years, $56.6 \pm 6.3$ years). All those participants were enrolled in the First People's Hospital of Zhaoqing during the period June 2012 to June 2013. Patients complicated with other clinical disorders, with history of malignancies, who received any therapies within 100 days before treatment were excluded from this study. The age and gender distributions were not significantly different between patient and control groups. The Ethics Committee of the First People's Hospital of Zhaoqing approved this study before the admission of patients and controls. All participants signed informed consent.

\section{Plasma and cell lines}

Fasting blood $(5 \mathrm{ml})$ was collected from each patient and control before the initiation of therapies. Blood samples were injected into EDTA tubes, and the tubes were centrifuged at $1200 \mathrm{~g}$ for $15 \mathrm{~min}$ to collect plasma.

AC16 human cardiomyocyte cell line (EMD Millipore, USA) was used. DMEM containing $1 \%$ penicillin and streptomycin as well as $12 \%$ fetal bovine serum (FBS) was used as cell culture medium. Cell culture conditions were $37^{\circ} \mathrm{C}$ and $5 \% \mathrm{CO}_{2}$.

\section{Follow-up}

A 5-year follow-up study was carried out to monitor the survival of all $72 \mathrm{CHF}$ patients. Follow-up was carried out mainly by telephone, and an outpatient visit was performed in some cases. Patients who died of other causes, such as other diseases or traffic accidents, were excluded from this study.

\section{Elisa}

TGF- $\beta 1$ in plasma was detected by performing ELISA experiments using Human TGF$\beta 1$ Quantikine ELISA Kit (DB100B, R\&D Systems). Sensitivity of this kit was 15.4 pg/ $\mathrm{ml}$. Levels of TGF- $\beta 1$ in plasma were normalized to $\mathrm{ng} / \mathrm{ml}$.

\section{RT-qPCR}

Total RNA extractions from plasma and AC16 cells were performed using Ribozol (Thermo Fisher Scientific) reagent. Synthesis of cDNA was performed through reverse transcriptions using the RevertAid RT Reverse Transcription Kit (Thermo Fisher Scientific). All qPCR mixtures were prepared with the SYBR Green Quantitative RT-qPCR Kit (Sigma-Aldrich). $18 \mathrm{~s}$ rRNA or GAPDH was used as an endogenous control to normalize GASL1 and TGF- $\beta 1$ expression. All PCR reactions were repeated 3 times. Data were processed using the $2^{-\Delta \Delta C T}$ method. 


\section{Vectors and transient transfections}

GASL1 and TGF- $\beta 1$ overexpression vectors (pcDNA3.1) were constructed by Sangon (Shanghai, China). AC16 cells were cultivated to confluence of $70-80 \%$ and transient cell transfections were performed using Lipofectamine 2000 reagent (Thermo Fisher Scientific) with $10 \mathrm{nM}$ vector. Cells without transfections (control) and empty vectortransfected cells (negative control) were included as two controls.

\section{Measurement of apoptotic assay}

AC16 cells were harvested at $24 \mathrm{~h}$ after transfections. Cells were mixed with DMEM to prepare single cell suspensions $\left(3 \times 10^{4}\right.$ cells $\left./ \mathrm{ml}\right)$. A 6 -well plate was used to cultivate the cells with $2 \mathrm{ml}$ of cell suspension in each well. $150 \mu \mathrm{M} \mathrm{H}_{2} \mathrm{O}_{2}$ was then added into each well. Cells were cultivated for $24 \mathrm{~h}$, followed by digestion with $0.25 \%$ trypsin. Finally, staining with propidium iodide (PI) and Annexin V-FITC (Dojindo, Japan) was performed and apoptotic cells were detected by performing flow cytometry.

\section{Western blot}

AC16 cells were harvested at 24 h after transfections and total protein was extracted using RIPA solution (Sangon, Shanghai, China). Protein samples were denatured and 10\% SDSPAGE gel electrophoresis was performed. Following gel-transfer to PVDF membrane, blocking was performed in $5 \%$ fat-free milk for $2 \mathrm{~h}$ at room temperature. After that, membranes were incubated with TGF- $\beta 1$ (1: 1300, ab92486, Abcam) and GAPDH (1: 1300, ab8245, Abcam) primary antibodies at $4{ }^{\circ} \mathrm{C}$ overnight. Following that, membranes were further incubated with IgG-HRP goat anti-rabbit secondary antibody (1: 900, MBS435036, MyBioSource) for $2 \mathrm{~h}$ at room temperature. Signals were developed using ECL (Sigma-Aldrich) and data were normalized using Image J v1.46 software.

\section{Statistical process}

To obtain solid data, all experiments were repeated 3 times. Differences between patient and control groups were performed by performing an unpaired $t$ test. Differences among different cell transfection groups were analyzed by ANOVA (one-way) and Tukey test. Correlations between GASL1 and TGF- $\beta 1$ were analyzed by linear regression. Based on plasma levels of GASL1, the $72 \mathrm{CHF}$ patients were grouped into high $(n=35)$ and low $(n=37)$ groups (Youden's index). K-M plotter was used to draw survival curves, which were compared using the log-rank test. The level of statistical significance was $p<0.05$.

\section{Results}

\section{Altered levels of TGF- $\beta 1$ and GASL1 were observed in CHF patients}

TGF- $\beta 1$ and GASL1 in plasma were detected by ELISA and RT-qPCR experiments, respectively. Differences of plasma levels of TGF- $\beta 1$ and GASL1 were analyzed by performing an unpaired $t$ test. It was found that plasma levels of TGF- $\beta 1$ were significantly higher (Fig. 1a, $p<0.05$ ), while plasma levels of GASL1 were significantly lower (Fig. $1 \mathrm{~b}, p<0.05$ ) in CHF patients than in healthy controls. 


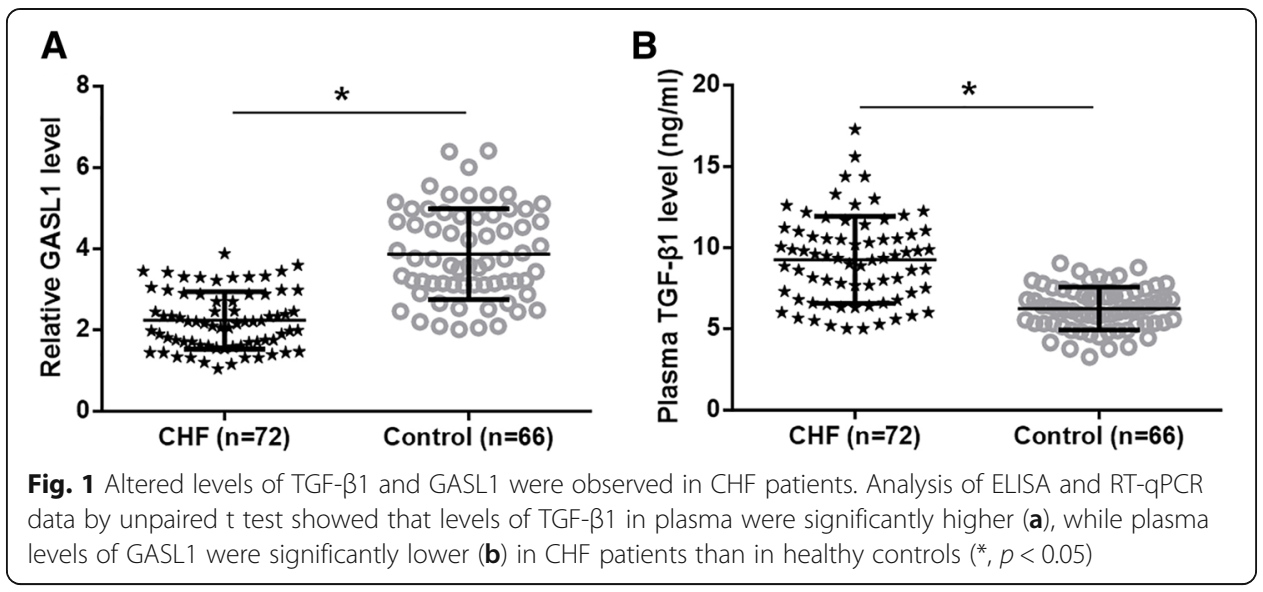

\section{TGF- $\beta 1$ and GASL1 were inversely correlated}

Correlations between GASL1 and TGF- $\beta 1$ were analyzed by linear regression. Plasma levels of TGF- $\beta 1$ and GASL1 were found to the significant and inversely correlated in CHF patients (Fig. 2a). However, in healthy controls, TGF- $\beta 1$ and GASL1 were not significantly correlated (Fig. 2b).

\section{Low plasma levels of GASL1 were closely correlated with poor survival}

Based on plasma levels of GASL1, the 72 CHF patients were grouped into high $(n=35)$ and low $(n=37)$ groups (Youden's index). The K-M method and log-rank test were used to plot and compare the survival curves. It was found that patients with low plasma levels of GASL1 had a significantly lower overall survival rate compared to patients with a high plasma GASL1 level (Fig. 3).

\section{GASL1 downregulated TGF- $\beta 1$ to inhibit AC16 cell apoptosis}

At $24 \mathrm{~h}$ after transfections, expression data were analyzed by one-way ANOVA and Tukey test to find the differences among groups. Expression levels of TGF- $\beta 1$ and GASL1 were significantly increased in AC16 cells compared to two controls (Control, C; Negative control, NC; Fig. 4a; $p<0.05$ ). In addition, TGF- $\beta 1$ overexpression failed to affect GASL1 in AC16 cells (Fig. 4b), while GASL1 overexpression mediated the

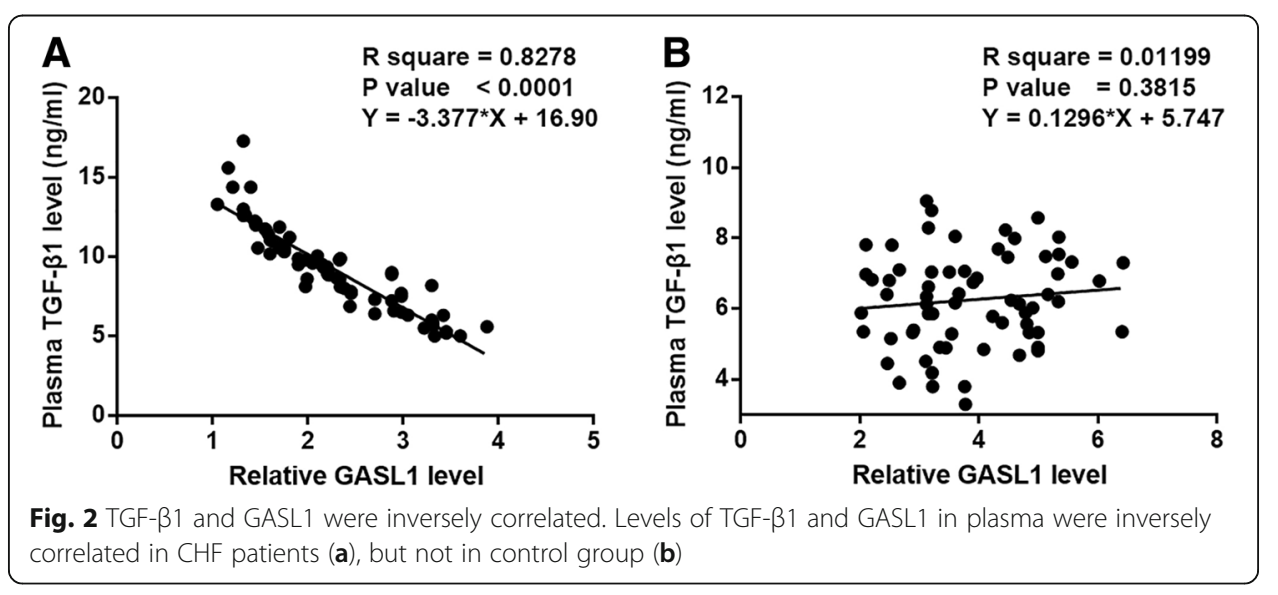




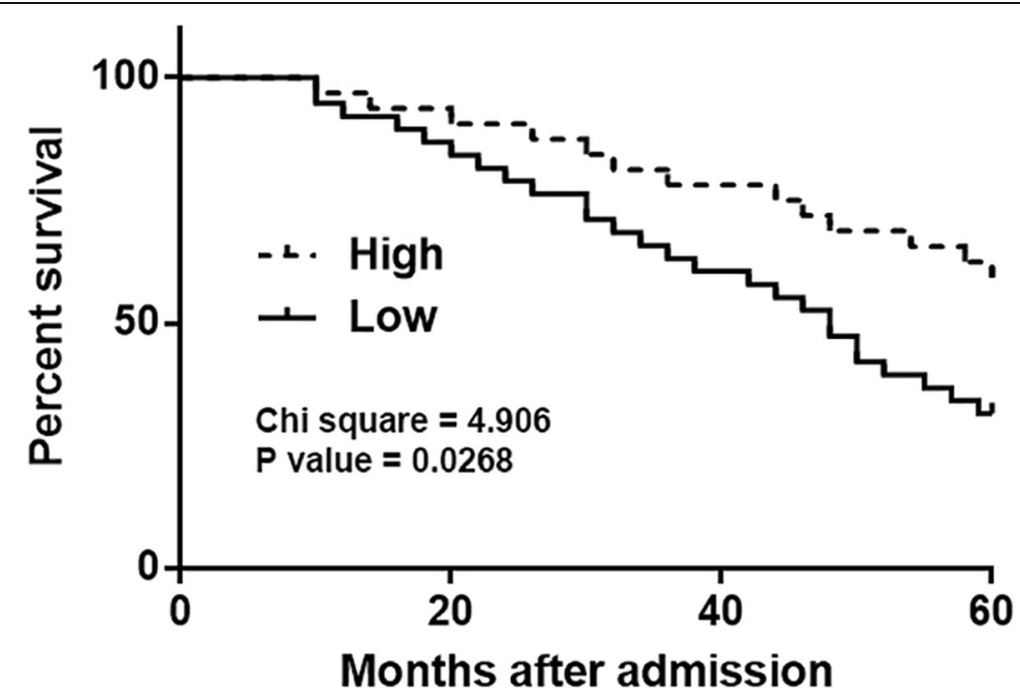

Fig. 3 Low plasma levels of GASL1 were closely correlated with poor survival. Analysis of survival data showed that low plasma levels of GASL1 were closely correlated with poor survival
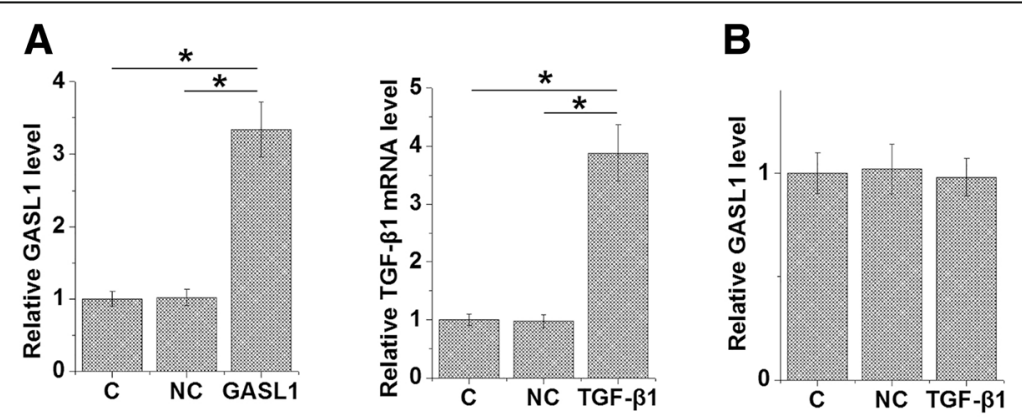

C

C NC TGF- $\beta 1 \quad$ D
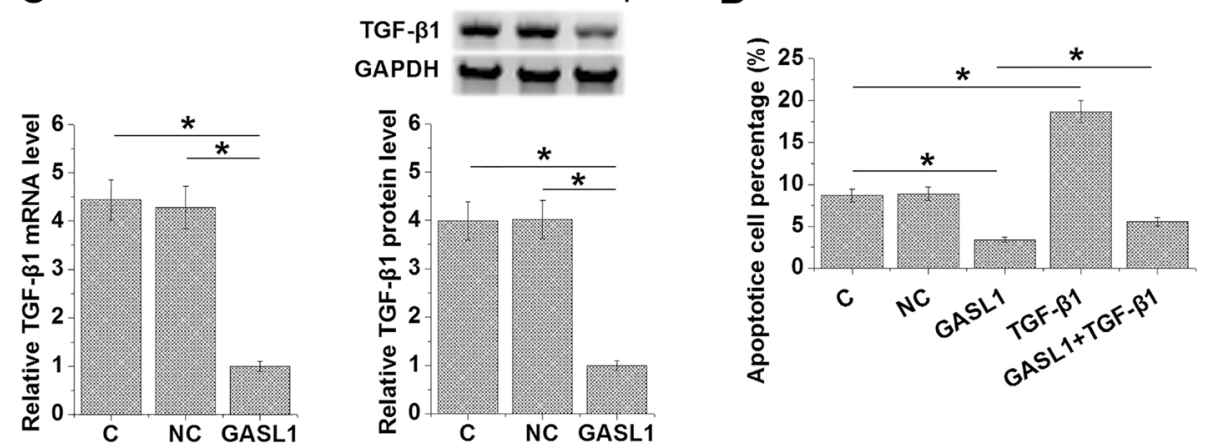

Fig. 4 GASL1 downregulated TGF- $\beta 1$ to inhibit AC16 cell apoptosis. Expression data analysis showed that expression levels of TGF- $\beta 1$ and GASL1 were significantly increased in AC16 cells compared to two controls (Control, C; Negative control, NC) at $24 \mathrm{~h}$ after transfections (a). In addition, TGF- $\beta 1$ overexpression failed to affect GASL1 in AC16 cells (b), while GASL1 overexpression mediated the downregulation of TGF- $\beta 1$ at both mRNA and protein levels (c). Cell apoptotic data analyzed by one-way ANOVA and Tukey test showed that overexpression of GASL1 led to decreased, while TGF- $\beta 1$ overexpression led to increased apoptotic rate of cardiomyocytes under $\mathrm{H}_{2} \mathrm{O}_{2}$ treatment. In addition, TGF- $\beta 1$ overexpression attenuated the effect of GASL1 overexpression $(\mathbf{d})(*, p<0.05)$ 
downregulation of TGF- $\beta 1$ at both mRNA and protein levels (Fig. 4c, $p<0.05$ ). Cell apoptotic data analyzed by one-way ANOVA and Tukey test showed that overexpression of GASL1 led to a decreased, while TGF- $\beta 1$ overexpression led to an increased apoptotic rate of cardiomyocytes under $\mathrm{H}_{2} \mathrm{O}_{2}$ treatment. In addition, TGF- $\beta 1$ overexpression attenuated the effect of GASL1 overexpression (Fig. $4 \mathrm{~d}, p<0.05$ ).

\section{Discussion}

In this study, we investigated the role of GASL1 in CHF. We proved that GASL1 was downregulated in CHF and predicted survival. Moreover, our in vitro experiments provided evidence that GASL1 overexpression may improve CHF by downregulating TGF- $\beta 1$.

With the efforts made in the treatment and prevention of CHF, the mortality rate of sudden death among CHF patients has dramatically decreased over the past several decades [12]. However, the overall mortality rate in those patients is still high and the cost of clinical treatment of this disease is a heavy burden on public health [13]. Therefore, it will be important to identify CHF patients with high risk of death and develop individualized therapeutic approaches to improve the survival of those patients. GASL1 was downregulated in cancer development $[9,10]$. In the present study we showed that GASL1 was downregulated in plasma of CHF patients and low levels of plasma GASL1 were closely correlated with the high mortality rate of CHF patients. Therefore, plasma GASL1 has predictive value for the survival of CHF patients. However, more clinical studies are needed to further confirm our conclusions.

TGF- $\beta$ signaling is activated during the development of CHF [14]. Activated TGF- $\beta$ signaling promotes the apoptosis of cardiomyocytes, thereby promoting the development of CHF [15]. In effect, inhibition of TGF- $\beta$ is considered as a promising therapeutic target for CHF $[15,16]$. Previous studies have shown that TGF- $\beta$ can regulate the expression of lncRNAs [17]. A recent study reported that TGF- $\beta$ signaling can also be inactivated by an IncRNA which is named GASL1 [10]. In the present study we showed that GASL1 was also an upstream inhibitor of TGF- $\beta 1$ in AC16 cells. Moreover, the interaction between TGF- $\beta 1$ and GASL1 participated in the regulation of the apoptosis of AC16 cells.

It is worth noting that TGF- $\beta 1$ only partially recovered the inhibited apoptosis of AC16 cells by GASL1. Therefore, GASL1 may also interact with other cellular factors to regulate AC16 cell apoptosis.

\section{Conclusions}

In conclusion, GASL1 was downregulated in CHF. GASL1 overexpression may improve CHF by inhibiting cardiomyocyte apoptosis through the inactivation of TGF- $\beta 1$.

Abbreviations

CHF: chronic heart failure; ELISA: enzyme-linked immunosorbent assay; FBS: fetal bovine serum; IncRNAs: Iong noncoding RNAs; PI: propidium iodide

Acknowledgements

Not applicable.

Authors' contributions

DHH did experiments work, analyzed data and was a major contributor in writing the manuscript. OYWB, ZL and XXS did experiment work and clinical research. HZY and ZWD: research design and manuscript editing. All authors read and approved the final manuscript. 
Funding

Not applicable.

\section{Availability of data and materials}

The datasets generated and/or analyzed during the current study are not publicly available due to research design, but are available from the corresponding author on reasonable request.

\section{Ethics approval and consent to participate}

The Ethics Committee of the First People's Hospital of Zhaoqing approved this study before the admission of patients and controls on Feb 11th, 2012 (Approval NO. 20120211FPHZQ322). All procedures performed in studies involving human participants were in accordance with the ethical standards of the 1964 Helsinki Declaration and its later amendments or comparable ethical standards. All patients and healthy controls signed informed consent.

\section{Consent for publication}

Not applicable.

\section{Competing interests}

The authors declare that they have no competing interests.

\section{Author details}

${ }^{1}$ Department of Anesthesiology, The First People's Hospital of Zhaoqing, Zhaoqing City, Guangdong Province 526000 People's Republic of China. ${ }^{2}$ Department of General Surgery, The First People's Hospital of Zhaoging, No. 9 Donggang East Road, Duanzhou District, Zhaoqing City, Guangdong Province 526000, People's Republic of China. ${ }^{3}$ Department of Anesthesiology, Fuwai Hospital Chinese Academy of Medical Sciences, No. 12 Langshan Road, Shenzhen City 518057, People's Republic of China. ${ }^{4}$ Department of Anesthesiology, Guangdong No. 2 Provincial People's Hospital, Guangdong Provincial Emergency Hospital, Guangzhou City, Guangdong Province 510317, People's Republic of China.

Received: 24 February 2019 Accepted: 30 May 2019

Published online: 13 June 2019

\section{References}

1. Weir HK, Anderson RN, Coleman King SM, Soman A, Thompson TD, Hong Y, et al. Heart disease and Cancer deaths trends and projections in the United States, 1969-2020. Prev Chronic Dis. 2016;13:E157.

2. Edelmann F, Knosalla C, Morike K, Muth C, Prien P, Stork S. Chronic heart failure. Dtsch Arztebl Int. 2018;115(8):124-30.

3. Writing Group M, Mozaffarian D, Benjamin EJ, Go AS, Arnett DK, Blaha MJ, et al. Heart disease and stroke Statistics-2016 update: a report from the American Heart Association. Circulation. 2016;133(4):e38-360.

4. Rosamond W, Flegal K, Furie K, Go A, Greenlund K, Haase N, et al. Heart disease and stroke statistics--2008 update: a report from the American Heart Association statistics committee and stroke statistics subcommittee. Circulation. 2008;117(4):e25-146.

5. Bertinchant JP. Brain natriuretic peptide (BNP) and N-terminal-pro BNP in chronic haemodialysed renal failure. Arch Mal Coeur Vaiss. 2004;97(9):881-8.

6. Eaton CB, Pettinger M, Rossouw J, Martin LW, Foraker R, Quddus A, et al. Risk factors for incident hospitalized heart failure with preserved versus reduced ejection fraction in a multiracial cohort of postmenopausal women. Circ Heart Fail. 2016;9(10).

7. Heberto Herrera Garza E, Herrera Garza JL, Rodriguez Gonzalez H, Trevino Trevino A, Ibarra Flores M, Torre Amione G. Importance of tumor necrosis factor-alpha in the pathogenesis of heart failure. Rev Esp Cardiol. 2002;55(1):61-6.

8. Papait R, Kunderfranco P, Stirparo GG, Latronico MV, Condorelli G. Long noncoding RNA: a new player of heart failure? J Cardiovasc Transl Res. 2013;6(6):876-83.

9. Gasri-Plotnitsky L, Ovadia A, Shamalov K, Nizri-Megnaji T, Meir S, Zurer I, et al. A novel IncRNA, GASL1, inhibits cell proliferation and restricts E2F1 activity. Oncotarget. 2017:8(14):23775-86.

10. Su WZ, Yuan X. LncRNA GASL1 inhibits tumor growth of non-small cell lung cancer by inactivating TGF-beta pathway. Eur Rev Med Pharmacol Sci. 2018;22(21):7282-8.

11. Lim H, Zhu YZ. Role of transforming growth factor-beta in the progression of heart failure. Cell Mol Life Sci. 2006;63(22):2584-96.

12. Shen L, Jhund PS, Petrie MC, Claggett BL, Barlera S, Cleland JGF, et al. Declining risk of sudden death in heart failure. N Engl J Med. 2017;377(1):41-51.

13. Ponikowski P, Anker SD, AlHabib KF, Cowie MR, Force TL, Hu S, et al. Heart failure: preventing disease and death worldwide. ESC Heart Fail. 2014;1(1):4-25.

14. Wang Q, Usinger W, Nichols B, Gray J, Xu L, Seeley TW, et al. Cooperative interaction of CTGF and TGF-beta in animal models of fibrotic disease. Fibrogenesis Tissue Repair. 2011;4(1):4.

15. Chu W, Li X, Li C, Wan L, Shi H, Song X, et al. TGFBR3, a potential negative regulator of TGF-beta signaling, protects cardiac fibroblasts from hypoxia-induced apoptosis. J Cell Physiol. 2011;226(10):2586-94.

16. Edgley AJ, Krum H, Kelly DJ. Targeting fibrosis for the treatment of heart failure: a role for transforming growth factorbeta. Cardiovasc Ther. 2012;30(1):e30-40.

17. Yuan JH, Yang F, Wang F, Ma JZ, Guo YJ, Tao QF, et al. A long noncoding RNA activated by TGF-beta promotes the invasion-metastasis cascade in hepatocellular carcinoma. Cancer Cell. 2014;25(5):666-81.

\section{Publisher's Note}

Springer Nature remains neutral with regard to jurisdictional claims in published maps and institutional affiliations. 